\title{
Neros, muchachos e novos homens. Cultura, violência e reciprocidade na problematização da masculinidade*
}

\begin{abstract}
Marco Julián Martínez-Moreno**
Resumo

A categoria "cultura" tem sido importante para a constituição da antropologia como disciplina, pois ela é fundamental para pensar a relação nós/outros do projeto moderno de sociedade. Nas políticas públicas que conjugam a análise de gênero na afirmação de direitos humanos, essa categoria, adjetivada como patriarcal, afirma desigualdades entre homens e mulheres como violência, motivo pelo qual são propostas formas de "mudança cultural". Neste artigo reflito sobre duas concepções de cultura na abordagem da relação entre masculinidade e violência em Bogotá, Colômbia, as quais mostram uma tensa relação entre o projeto de sociedade igualitária e as formas de autoridade local. A partir da noção de reciprocidade, revalorizo a ideia de cultura para pensar a conformação de relações de gênero nos contextos locais nos quais as políticas públicas sociais exercem processos de subjetivação cidadã, para os indivíduos se conceberem como sujeitos de direitos.
\end{abstract}

Palavras-chave: Cultura, Reciprocidade, Gênero, Violência, Modernidade.

* Recebido em 05 de janeiro de 2014, aceito em 30 de janeiro de 2017.

** Pós-doutorando do Programa de Pós-Graduação em Antropologia Social do Museu Nacional, Universidade Federal do Rio de Janeiro (UFRJ), Rio de Janeiro, RJ, Brasil. Investigador associado do Instituto de Estudos Comparados e Administração Institucional de Conflitos, InEAC, e do Centro de Estudios Sociales da Universidade Nacional de Colômbia. Bolsista da FAPERJ. akkmim@gmail.com 

na problematização da masculinidade

\author{
Neros, Muchachos and New Men. Culture, Violence and Reciprocity in \\ the Problematization of Masculinity
}

\begin{abstract}
The category "culture" has been important to the constitution of anthropology as an academic discipline, because it is essential for considering the relationship between "ourselves" and "others" in the modern project of society. In the context of public policies that value gender analysis as a means to affirm human rights, this category, classified as "patriarchal", affirms that inequalities between men and women are a form of "violence", for which reason policy makers propose forms of "cultural change". In this article I reflect on two different concepts of culture to consider the relations between masculinity and violence in Bogota, Colombia. This reveals tensions between a project for an equalitarian society and local forms of authority. Based on the notion of reciprocity, I reevaluate the idea of culture to consider the way gender relations are shaped in local contexts where public policies foster processes of citizen subjectivation, so that individuals can conceive of themselves as subjects with rights.
\end{abstract}

Keywords: Culture, Reciprocity, Gender, Violence, Modernity. 
Ser ñero, muchacho e novo homem. Cultura, reciprocidade e gênero na relação entre violência e masculinidade

A categoria "cultura" foi importante para a constituição da antropologia como disciplina, sendo fundamental para pensar a relação nós/outros do projeto moderno de sociedade. Ao longo do século XX, ela foi apropriada por diversos agentes que a partir dela reivindicam sua existência social, seja afirmando diferenças ou igualdades em relação a noções individualistas sobre a dignidade humana. Nas políticas públicas que conjugam a análise de gênero na afirmação de direitos humanos, a categoria "cultura", adjetivada na maioria das vezes como patriarcal, tem sido central para afirmar desigualdades entre homens e mulheres e criar variados objetos de "mudança cultural". Os homens $e$ as masculinidades têm se tornado objeto de atenção acadêmica $e$ política, considerando as identidades e práticas dos homens, como categoria universal, como produto da cultura e como obstáculo para o reconhecimento da dignidade humana das mulheres (Martínez-Moreno, 2014).

Neste artigo, reflito sobre duas concepções de cultura com as quais tenho dialogado ao longo da minha trajetória profissional como antropólogo no campo das masculinidades em Bogotá, Colômbia. Elas mostram a tensa relação entre o projeto de sociedade igualitária e as formas de autoridade local. Afirmo que a categoria "cultura" constitui um anti-valor para as políticas de gênero, as quais assumem uma perspectiva individualista das relações sociais. Como proposta, considero que uma análise da reciprocidade é útil para pensar a constituição de relações de gênero, moralidades e posições éticas que contrastam com a perspectiva liberal de assumir a relação indivíduo-sociedade. A partir da noção de reciprocidade, revalorizo a ideia de cultura para pensar os contextos locais nos quais as políticas públicas sociais exercem processos de subjetivação cidadã, para os indivíduos se conceberem com Direitos Humanos. 


\section{A masculinidade $e$ a mudança cultural}

Trabalhei como gestor de política pública entre 2007 e 2009 no projeto governamental Acceso a la Justicia Familiar y Atención Integral a las Violencias Intrafamiliar y Sexual, conhecido pelo código administrativo 375 (DABS, 2005). O 375 conjugava o propósito de garantir os direitos humanos das mulheres e das crianças com o princípio de igualdade entre homens e mulheres por meio de ações de prevenção, atenção e eliminação das violências que aconteciam no interior da família. $\mathrm{O}$ projeto integrava desenvolvimentos legislativos de convenções e tratados internacionais (CEDAW e Belém do Pará), bem como dados de estudos de gênero que justificavam o direito a uma "vida livre de violência" para as mulheres. As autoras do projeto, funcionárias que se identificavam como feministas, também tinham como referente o artigo constitucional relativo à igualdade entre homens e mulheres, bem como leis e normativas penais sobre proteção de bens jurídicos tutelados no indivíduo, o principal deles sendo a dignidade humana.

O 375 considerava que a violência perpetrada pelos homens remetia à cultura da violência ${ }^{1} e$ à cultura patriarcal, que geravam privilégios de poder para os varões, cujo efeito eram

\footnotetext{
1 "Cultura da violência" é uma maneira de entender o conflito armado de mais de cinquenta anos na Colômbia, que reúne estudos sociológicos $e$ historiográficos. Essa categoria assume que o deslocamento de populações camponesas às grandes cidades, a causa dos enfrentamentos entre diversos setores armados do país, especialmente entre guerrilheiros e exército, gera camadas de jovens traumatizados que integram os setores marginais e pobres da cidade. Esses jovens viram delinquentes e reproduzem a violência experimentada no campo nas cidades. Esse tipo de explicação tem sido frequente no discurso político colombiano, justificando ações estatais de uso da força armada e o desenho de políticas de paz e leis que buscam garantir o direito à paz desde a década de 1980. Essas políticas têm se sofisticado passando do enfrentamento do conflito armado para a intervenção da família, considerando-a núcleo da sociedade (ver Martínez-Moreno, 2013).
} 
desigualdades nas relações e vulnerabilidades para as mulheres. ${ }^{2}$ Esses privilégios eram demostrado com o uso de estatísticas dos tipos penais de violência intrafamiliar e violência sexual, que reportavam números maiores, ao longo do tempo, de vítimas nas delegacias para a família, delegacias de polícia, escolas e hospitais públicos. A linha de prevenção do projeto (que complementava a penalização dos agressores e a atenção às vítimas) contemplava o empoderamento das mulheres e a transformação da identidade de gênero dos homens, através dos conversatorios. Estes últimos propunham a reflexão sobre a aquisição da identidade de gênero, a sexualidade e os direitos para os homens se posicionarem de maneira crítica perante seu processo de criação e relações familiares atuais e assumirem então uma "nova masculinidade". Os participantes, possuindo idades e condições sociais variadas, $e$ vindo dos bairros periféricos de Bogotá, assistiam de maneira compulsória às oficinas, sendo elas um pré-requisito para receber outros benefícios das instituições públicas.

Como facilitador das oficinas, eu devia fazer com que eles compreendessem o uso naturalizado da violência, que era reproduzido nas relações cotidianas com suas companheiras $e$ seus filhos. Deveria fazer com que percebessem o processo de transmissão de valores da masculinidade que legitimava a agressividade como estruturante da verdadeira forma de ser homem. Buscava que eles concebessem a ideia de direito como um bem individual universal e não como privilégio masculino. Por último, procurava que eles reconhecessem a autonomia das mulheres e a necessidade de estarem presentes na criação dos filhos. Desse modo, o 375 pressupunha que eles pudessem compartilhar o poder, favorecendo o exercício dos direitos e o relacionamento igualitário com as mulheres. Essa era a estratégia para, em última instância, implantar a "democracia familiar": conceito da Corte Constitucional colombiana para responder à

2 Para considerações acerca da vinculação política entre as ideias da cultura da violência e a cultura patriarcal como pressupostos conceituais do tipo penal "violência intrafamiliar" na Colômbia, ver Martínez-Moreno (2013). 
cultura da violência desde o lar, e que assumia que a família era o contexto de formação de sujeitos de direito.

Ser facilitador dessas oficinas era meu primeiro trabalho como bacharel em antropologia. Politicamente, eu experimentava uma contradição: eu não concebia necessariamente a cultura como objeto de mudança através da transformação individual, pois isso parecia algo contrário ao princípio de multiculturalismo, também integrante da Constituição Política colombiana. Em virtude de minha formação, para mim a cultura era um objeto de pesquisa e teorização de populações, como uma possessão única, histórica e contextualmente compreendida, que dava sentido a pensamentos, ações e reflexões sobre a vida cotidiana. Uma noção de cultura que bebe no culturalismo norte-americano, base histórica da antropologia exercida na Colômbia. Essa concepção da cultura, mais próxima de postulados de autodeterminação de sociedades indígenas, gerava controvérsias em fóruns de debate político e acadêmico sobre justiça e equidade de gênero: a cultura não podia estar acima da igualdade entre homens $e$ mulheres. Notei que a noção de cultura não era unívoca; às vezes remetia a um arranjo universal que se traduzia na dominação masculina, outras vezes a diferenças que não eram compatíveis com o princípio de igualdade. Em todo caso, a cultura aparecia como um resíduo a ser transformado ou erradicado por esquemas de intervenção psicossocial e jurídica.

Naquela época, eu considerava que os funcionários do 375 objetivavam a cultura como folclore, circunscrevendo-a às populações pobres da cidade - o público alvo do projeto - $e$ classificando como tradicionais tanto pensamento como práticas locais. Desse modo, Bogotá, como cidade, tinha seres e lugares culturais que representavam carência de cidadania, ao mesmo tempo que pobreza econômica. Ser pobre era ser diferente culturalmente, e essa diferença encarnava a violência. As culturas da violência e patriarcal estavam localizadas na mente das pessoas moradoras das periferias da cidade e nos bairros marginais. Nesse sentido, é possível entender uma visão psicologizante da cultura, a qual permite pensar a masculinidade (e a violência) transmitida 
através da criação, na qual são adquiridos valores, configurando a identidade de gênero e reproduzindo posteriormente a cultura.

O projeto 375 , como outros que articulam a produção dos estudos de gênero e feministas, tentava dar conta de diferenças na garantia de direitos como desigualdades entre indivíduos, constituindo populações em oposição ao ideal de cidadão. Esse esquema assume a violência experimentada ou sofrida como um fato social total, que permite ver em conjunto as relações de poder da cultura patriarcal, e que, à luz da doutrina dos direitos humanos, resulta ilegítima como fonte de direito. A cultura patriarcal era apresentada como um fenômeno universal que carrega um passado indesejado, que impossibilita a liberação do indivíduo da tradição, criando uma realidade social problemática. Sobre esta última, legitimavam-se exercícios de governo que concebiam homens definidos culturalmente $e$ mulheres com o estatuto ontológico de seres humanos.

\section{Reciprocidade e cultura}

A categoria de cultura é problemática em relação a formas de governo contemporâneas, e dentro da antropologia está associada a um debate igualmente complexo. Autores como James Ferguson e Akhil Gupta (1997) ou Lila Abu-Lughod (1991) são críticos da noção de cultura, considerando-a produto do imperialismo, ou mesmo o equivalente à noção de raça, permitindo ver a posição de poder de quem nomeia como cultural um fenômeno. Marshall Sahlins (1997) reconstrói uma história da categoria, mostrando como, antes de ser produto do imperialismo, ela aparece como reação de românticos do século XVIII de áreas consideradas relativamente atrasadas (a Alemanha e Rússia) diante do Iluminismo francês e inglês. Os pensadores românticos defendiam as tradições locais e particularidades regionais contra o arquétipo de um homem universal e atomizado, representante da sociedade.

O pensamento iluminista, consistente com uma sensibilidade burguesa, considerava que o uso da razão traria a emancipação 
do homem e o livraria das amarras e ilusões da tradição, estabelecendo uma linha evolutiva que levaria o homem à civilização. Esse homem do iluminismo tem se manifestado como sujeito cartesiano, o homem economicus, homo sapiens ou como cidadão com direitos e responsabilidades, do qual deriva o homem dos direitos humanos. Diante desse universalismo na base da ideia de progresso, as teorias da Kultur emergem como forma de reivindicar as ideias nacionais ante o projeto civilizatório. Kultur supõe a valorização da diferença, colocando as expressões em relação simétrica e igualitária, cujo efeito são variedades de cultura. O termo civilisation supóe uma escala valorativa entre as expressões de diferença, instaurando estágios evolutivos entre as nações, cujo efeito são graus de civilização. Kultur tem sido fundamental para as reivindicações étnicas de povos indígenas, muitas vezes em confrontação à universalidade da retórica dos direitos humanos, como nos casos de circuncisão feminina ou acordos matrimoniais. Ao mesmo tempo, tem servido para os agentes da civilisation designarem o outro, objeto da empresa colonial. Usualmente Kultur tem sido utilizada pelos antropólogos para refletir acerca das relações de comunidades étnicas com sociedades nacionais.

Para Sahlins, entre outros autores, a antropologia emerge na tensão entre Iluminismo e Romantismo, a qual remete a outra tensão: o individualismo radical do mito de origem hobbesiano em contraposição ao homem como ser social herderiano. Em outras palavras, o modelo da societas em relação ao modelo da universitas (Dumont, 1985). De modo geral, o movimento dos antropólogos foi o de discutir paradigmas iluministas presentes na filosofia, economia, psicologia e direito quando faziam referência a instituições nativas que eram caraterizadas em estágios de barbárie. Ao reconhecer uma lógica inerente às instituições da Kultur, a antropologia considerava o pensamento iluminista como etnocêntrico.

Durante os séculos XIX e XX, a antropologia anti-iluminista que se desenvolveu nos Estados Unidos com Franz Boas e seus estudantes fez uma crítica ao evolucionismo e ao individualismo, 
negando sua universalidade. $\mathrm{O}$ estudo dos significados permitiu aos culturalistas norte-americanos entender o indivíduo e sua materialidade em correspondência a um meio cultural específico, em diálogo com a noção de "gênio de um povo" do romantismo alemão e reproduzindo a relação indivíduo-sociedade (Boas, 1986; Stocking, 1968). Para as escolas inglesa e francesa ao longo do século $\mathrm{XX}$, a cultura seria mais como uma camada ideológica superposta às relações sociais. As sociedades eram o objeto da reflexão dessas escolas, seguindo o paradigma da civilisation, entendidas como entidades reais, sendo a cultura um epifenômeno (Kuper, 1983). Em todo caso, a reflexão sobre como era constituído o elo social não excluiu a noção dos simbolismos que permitem tal constituição, ora como força moral que permite a coesão social, ora como sistemas classificatórios que organizam a lógica de pensamento $e$ o conhecimento de indivíduos $e$ coletivos. A cultura passa a ser concebida como um sistema simbólico que se expressa pela linguagem em relação à morfologia social.

Até aqui, fiz uma breve história da categoria de cultura na antropologia como contraponto de referência do seu uso político fora dos debates de intervenção jurídica e psicossocial. Agora, vou me referir à ideia de reciprocidade, como proposta para a análise do gênero, entendido como ato de classificar (ver Strathern, 2006), naquilo que podemos chamar de Kultur das populações alvo das políticas da civilisation.

A partir do trabalho de Malinowski (1973), entre outros autores, Marcel Mauss (2011) coloca a dádiva no centro da reflexão da constituição das relações sociais. As três obrigações encadeadas de dar, receber e retribuir, têm tido potencial heurístico para a antropologia. Elas mostram como existem relações nas quais circulam não só bens, mas palavras, valores, sentimentos e símbolos, que outorgam formas e conteúdos particulares às relações. Aqui a noção de pessoa é importante, pois a partir dela é possivel pensar lugares morais, expectativas sociais, precedências e interdependência nas relações. $\mathrm{O}$ que circula não são só coisas, nem a representação da pessoa, mas a 
pessoa em si, mostrando, por um lado, a inalienabilidade entre a pessoa e o conteúdo da relação social, e por outro como o que circula faz parte da noção de si dos doadores. Cada circuito constitui um sistema de comunicação cuja função é integrar, ou melhor, constituir a sociedade, rompendo os laços puramente biológicos e superpondo a isso o universo da cultura.

Pensar na reciprocidade permite pensar a relação entre individualidade e posição social, questões sobre agência $e$ estrutura, hierarquia, assimetria e poder. Com isso, debate-se o suposto da contratualidade da sociedade e o princípio de interesse do indivíduo moderno. Também mostra-se como aquilo que podemos chamar de cultural possui um ordenamento, uma lógica, uma forma e um conteúdo circunstancial. Daqui deriva que mesmo encontrando morfologias similares em contextos diferentes, a forma não explica o conteúdo da relação, razão pela qual o analista deve abandonar o uso de metáforas universalizantes que explicam a sociedade.

A discussão sobre dádiva e gênero remete à circulação e ao valor das mulheres nas trocas mediadas pelos homens, que remontam às considerações de Cláude Lévi-Strauss (1981) acerca do potencial generativo de elementos da vida social através da troca: o estabelecimento da aliança pelo intercâmbio de mulheres, e ao desenvolvimento crítico dessa ideia por Gayle Rubin (1975). Esta última inaugura a noção de economia política do sistema sexo/gênero para compreender como se produz a transformação da fêmea (sexo biológico) em uma mulher confinada ao espaço doméstico (gênero) durante a troca, momento no qual elas passam a ser objeto de intercâmbio. ${ }^{3}$

Marylin Strathern (1984a; 1984b; 2006) problematiza essa posição. Partindo da sua etnografia entre os Hagen, ela amplia o significado do sistema proposto por Rubin. A autora estabelece

3 Vale a pena lembrar a ativa produção intelectual de antropólogas feministas e outras pensadoras, a partir da década de 1960, que inauguraram na antropologia um rico debate acerca de supostos iluministas e o papel da mulher na produção etnográfica, problematizando a dicotomia natureza/cultura que explicava as diferenças de gênero (ver Strathern, 2006; Moore, 2007). 
como objeto analítico as práticas de conhecimento melanésias, que quando contrastadas analogicamente com as do Ocidente, desvelam diferenças no conteúdo de categorias antropológicas, feministas e melanésias. Centrando a atenção na socialidade, a autora propõe abordar processos de identificação de gênero, atualizando os repertórios cosmológicos em contextos particulares. A proposta de incorporar as teorias nativas implica assumir o sujeito posicionado nas relações, para produzir efeitos determinados no outro da relação. Strathern relaciona processos de conformação da subjetividade e a identificação de gênero com relações de troca em níveis mais abrangentes, problematizando a dicotomia publico/doméstico. Configuram-se as relações diferenciadas pelos sentimentos, gerando modos específicos de agir em relação a estruturas de autoridade (ver Moore, 2007).

Como enunciado antes, na troca, doador e receptor não têm o mesmo status nem precedência, configurando uma relação de poder; o cálculo da equivalência das pessoas e coisas trocadas não implica (nem é desejável) que haja o mesmo valor, impossibilitando o equilißbrio, adicionando valor à relação estabelecida, segundo critérios temporais e de distância social (ver Sahlins, 1983). Como já anunciava Mauss, estabelecer uma relação de aliança implica adquirir dívidas em outra série de relações, as quais criam outras dádivas $e$ impõem novas obrigações $e$ precedências entre pessoas morais. Nesse sentido, e voltando à discussão proposta por Lévi-Strauss, na troca de mulheres entre clãs, por exemplo, não há equivalências como ser humano, como indivíduo no sentido ontológico, pois as dívidas ativadas nas relações são diferentes entre a pessoa da irmã que sai $e$ da esposa que chega. Cada uma delas tem direitos e obrigações particulares com cada clã, pelo qual os direitos são relativos à instituição $e$ o poder constitui-se na relação; eles não são propriedade do indivíduo, mesmo que ideologicamente sejam concebidos como tal.

Faço essa breve alusão à ideia de reciprocidade para revisitar meu trabalho como antropólogo e facilitador de oficinas sobre novas masculinidades. Em 2005, eu assumia uma noção de 
cultura similar à do culturalismo norte-americano, agenciava um discurso político igualitário e notava que as falas e representações dos homens alvo do projeto 375 distanciavam-se ou contrastavam com os supostos acadêmicos que informavam o saber acadêmico $e$ político da relação entre violência e masculinidade. Agora apresento uma situação etnográfica com jovens entre 12 e 18 anos, moradores de rua institucionalizados, caraterizados pela administração pública como "em risco social", moradores de um bairro periférico de Bogotá, ocupado por migrantes de origem rural e pessoas deslocadas pelo conflito armado procedentes de várias regiões do país (ver Jimeno et alii, 2007). Como situação social, as categorias e representações dos jovens fazem parte de um discurso localizado, que encontra sentido na interação entre a proposta filosófica do projeto e a experiência dos jovens. Não apresento um "discurso nativo" reflexo da masculinidade local, mas o diálogo entre categorias liberais com categorias de direito $e$ parentesco que dão conta de relações de reciprocidade dos ñeros, bem como outra noção de dignidade para si, privilegiando a ideia de ser papá à de novo homem.

\section{Neros, muchachos e novos homens}

Os jovens moradores de rua que recorriam a um centro de acolhida temporal eram chamados de muchachos pelo Padre Márquez, coordenador do centro, sendo esse um tratamento para se referir aos mais jovens, sempre com uma conotação de bondade. ${ }^{4}$ Eles tinham que passar pelo ciclo de oficinas como parte de um currículo de ressocialização e formação para o trabalho. Nós mantivemos contato durante quase quatro meses, uma ou duas vezes por semana, durante o tempo da oficina $e$

4 Muchacho também serve para se referir a subordinados dentro de uma organização, aprendizes de um ofício ou seguidores de uma autoridade. Por exemplo, no exército, os muchachos são os soldados rasos. $\mathrm{O}$ ex-presidente Álvaro Uribe, controvertido pelos seus nexos políticos com o paramilitarismo, se referia aos militares implicados em delitos de lesa humanidade como os buenos muchachos. 
compartilhando espaços de lazer dentro do instituto. Os muchachos me chamavam de profe, contração para professor, evidenciando a minha autoridade na oficina. Pouco tempo depois me chamavam de cucho, termo para se referir a uma pessoa mais velha, com a qual há uma relação de respeito, afeto e confiança. Usualmente é usado para se referir ao pai, aos avós ou à mãe, cucha.

Depois de umas semanas, alguns deles me chamavam de $m i$ ñero, termo para se referir entre pares no parche. ${ }^{5}$ Nero é um termo pejorativo usado pelos moradores de Bogotá para se referir a alguém mais pobre, sem educação, de mau gosto e aos moradores de rua. Os muchachos se chamavam entre si de ñeros, mas não gostavam que outros, alheios, os chamassem dessa forma. Era uma questão do tom empregado para passar de uma identificação a um insulto. Eu os chamava de jóvenes, cuja conotação moral é similar a de muchacho, depois de parce ou parcero, termos menos formais de reconhecimento igualitário similar a ñero, mas com uma menor carga de estigma.

A reflexão sobre gênero começou na primeira oficina sobre "padrões de criação e identidade masculina" com as perguntas "o que é ser um bom homem?" e "como me ensinaram a ser homem?". Nesse momento, os jovens não queriam falar $e$ pareciam tímidos. Eles estavam acostumados a escutar o adulto na sala de aula. Um deles mencionava que nunca tinha se perguntado isso. Para mim era uma pergunta apenas óbvia. Falei sobre como os homens na Colômbia eram os possuidores da autoridade, o que lhes dava poder para controlar esposa e filhos. Percebi que eles eram novos, ainda sujeitos à autoridade de um algum adulto em casa ou na instituição de acolhida. Perguntei sobre como eles experimentavam esse poder e como isso podia

${ }^{5}$ Parche se refere a um grupo de amigos no bairro, sendo uma acepção dos ñeros do lugar onde há vínculos sociais e uma sensação de ser parte do grupo, de não estar sozinho. Também é uma palavra associada ao consumo de drogas como maconha ou crack (Góngora, 2013). 
traduzir-se em vulneração de direitos, tanto deles quanto das mulheres na família.

Alguns deles se sentiram interpelados e mencionaram que eram recriminados e castigados pelos adultos da casa: mãe, tios, avós, padrastos ou irmãos mais velhos, por não obedecer. $\mathrm{O}$ mesmo se dava no centro de acolhida, no bairro ou em qualquer lugar onde eles estivessem. Mas o castigo sempre era justificado, parecia que o adulto sempre tinha a razão. Nunca escutei quais eram os direitos desconhecidos pela imposição dos homens adultos, mas sim a desconsideração da posição - sua voz - deles sobre as situações cotidianas. Depois, com o decorrer das oficinas, particularmente aquela relativa aos direitos sexuais e reprodutivos, notei que a noção de direito positivo era uma convenção que funcionava para se relacionar precisamente com as instituições públicas, mas não era usada para se referir às situações na casa. $\mathrm{A}$ desconsideração se expressava em uma linguagem emocional, mostrando uma distância entre o reconhecimento pelo direito como bem objetivável que o indivíduo possui e o reconhecimento como consideração de si pelos outros, sendo uma categoria construída na relação.

$\mathrm{Na}$ oficina sobre "novas formas de ser homem" falei sobre como construir relações equitativas fora do autoritarismo e da importância de se aceitar outras formas de masculinidade diferentes da costumeira. Expliquei o conceito de "masculinidade hegemônica" que definia os atributos de um "verdadeiro homem" como dominante, heterossexual, machista, protetor, provedor econômico, entre outros atributos de gênero que pretendiam ser desnaturalizados. Eu argumentava que ser homem era uma construção social e não um atributo inato ou condição. Os jovens só escutavam, talvez tentando compreender meu argumento. Eu mencionava que existiam múltiplas formas de ser homem, as quais também eram legítimas, mas que muitas vezes eram subordinadas a essa imagem idealizada do masculino.

Diante dessa descrição, mais do que reagir criticamente, os jovens concordaram. Fiquei perplexo porque acreditava que eles se identificariam facilmente com outras masculinidades pelo fato 
de eles serem pessoas estigmatizados socialmente. Os jovens consideravam essa imagem do "homem hegemônico" como modelo a se seguir. Com exceção do atributo "machista", os outros eram bem-vindos. Para eles, ser machista tinha uma conotação negativa associada a exercer violência contra as mulheres, as quais deviam ser protegidas, mas não era uma categoria que englobava ou era equiparável à experiência de ser homem. Eu argumentava que esses atributos todos faziam parte de uma estrutura de poder que procurava o controle da vida das mulheres e crianças. Então, essa imagem desejada por eles implicava, no fundo, ser machista. Eles não concordaram.

Os atributos do homem hegemônico, menos o machismo, descreviam a valorizada figura do papá ou cucho, responsável pelos integrantes da família, exemplo do comportamento a se seguir no presente e no futuro dentro e fora da casa. O papá era descrito como trabalhador, pré-requisito para ser responsável $e$ estava ligado à noção de sacrifício, com o qual o projeto individual de homem solteiro, capaz de estar com muitas mulheres, era posto em um segundo plano, privilegiando o status de ser pai e esposo ao prazer e ao conforto que outorga a libertad. Este valor, se não era cuidado pelos cuchos e vigiado por si mesmo, podia virar libertinaje, levando ao vicio na rua, lugar que eles já conhecem bem.

Para os ñeros a dicotomia casa/rua era significativa. Na casa se convivia com mulheres: as mães ou cuchas, as irmãs, tias $e$ avós, as quais mereciam respeito e ofertavam carinho e proteção, enquanto eles procuravam o reconhecimento da sua individualidade, da sua visão de mundo. Muitas vezes em casa eles eram desvalorizados como irresponsables, sem capacidade de aportar economicamente, mas amados como filhos pelas cuchas. ${ }^{6}$

${ }^{6}$ Em outras oficinas realizadas com homens adultos, já sendo pais de família muitos deles, foi recorrente escutar que aportar economicamente era um dos signos que dignificava um papá. Mencionavam como se sentiam mal quando não podiam trazer dinheiro para casa (seja como pais, esposos ou filhos), experimentando então impotência, o que os levava a ter conflitos com outras pessoas na família, especialmente as mulheres, por se sentirem humilhados. 
Na casa, morava a familia, idealizada como agente de educação $e$ exemplo de convivência, concordando com a expectativa do Padre Márquez de ela ser o núcleo da sociedade. Não obstante, a experiência em casa era desconfortável e cheia de problemas, pois estar nela produzia medo e tédio. Na rua, eles procuravam prazer na maconha em companhia de pares, os amigos. Na rua também existia o perigo da autoridade e de outras pessoas que os julgavam por serem agentes que não aportavam à vida em sociedade. A rua tinha uma temporalidade, não era possível ficar lá dia todo, porque existia o perigo de virar vago e ficar no vício, tornando-se morador de rua permanente.

Os ñeros aprendiam a administrar a experiencia no trânsito entre a casa e a rua. $\mathrm{O}$ sucesso nessa administração significava virar homem. A experiência traria dignidade dentro de casa através da provisão econômica, retribuição esperada pelas mulheres, gerando a expectativa de reconhecimento e bem-estar que se manifestava pelo carinho. Não ter experiência implicava não adquirir qualidades esperadas pelas mulheres em casa e pelos homens na rua $e$ nas instituições públicas, sendo classificados como irresponsáveis. Isso denotava problemas na definição da sua individualidade. $\mathrm{O}$ reconhecimento da sua experiência lhes permitiria circular com autoridade entre a casa e a rua, se relacionando como iguais com outros homens.

O diálogo na família, mais que ser uma relação horizontal de indivíduos que se reconheciam na sua singularidade, era uma relação direcionada dos mais velhos para os mais jovens, em um intercâmbio de experiencia por obediencia. Essa noção também era compartilhada e estimulada pelo padre, pela freira e pela assistente social do instituto de acolhida. Os jovens esperavam dos

Ressaltaram que eles não tinham emprego estável e que as mulheres tinham que sair para trabalhar e manter o lar, porém eles não gostavam das mulheres saírem à rua, porque achavam que facilmente elas se interessariam por outros homens. $\mathrm{O}$ medo era de serem traídos e abandonados. Assim, expressavam uma mudança dos papéis. Muitas das "causas da violência intrafamiliar" tinham a ver com a presença ou não do dinheiro, com a capacidade do homem de ser provedor econômico do lar, como atributo da dignidade de ser pai. 
pais conselhos para a vida cotidiana e para planejar o futuro. Os conselhos capitalizavam uma experiência de vida, a qual era socialmente reconhecida a partir do sucesso pessoal, da manutenção dos mais velhos e de tranquilidade e paz em casa. Tudo isso era materializável nas condições de infraestrutura da casa, na providência econômica do filho e na intensidade do amor de mãe. Um homem com experiencia era aquele que os ñeros queriam seguir. Os ñeros não viam tais homens na proposta de novo homem, na ideia de autonomia ou nos homens que circulavam em casa.

A cucha possuía um tipo de autoridade relacionada a sentimentos de afeto, carinho e proteção que gerava a obrigatoriedade de os jovens serem responsáveis por ela. Ela era a pessoa de máxima estima. Insultar a mãe representava uma grave ofensa entre eles, gerando as mais fortes reações de defesa da sua santidade, extensível às irmãs. Existia um vínculo de afeto $e$ cuidado com as mulheres da casa e elas eram, em última instância, a casa: os homens circulavam enquanto elas ficavam. O fato de a santidade ser violada por outros homens, padrastos particularmente, gerava ira e dor, mas também impotência. Os jovens não podiam confrontar aqueles homens. Por alguma razão que eles não compreendiam, a cucha mantinha o vínculo sentimental com esses violadores, incluindo a raiva na relação mãe-filho e gerando o sentimento de desconfiança, desesperança e ressentimento, sem, contudo, implicar a perda do amor materno e o carinho deles para elas. Ser violador era uma identificação depreciável, utilizada para desqualificar um par, uma ofensa máxima. Ser violador dizia respeito a ofender e transgredir o respeito da mãe ou das mulheres da casa, mas não o desconhecimento dos direitos individuais delas como mulheres. Nesse esquema, só uma figura alheia à casa, investida de poder institucionalizado, que podia exercer coerção e ter o poder da punição, podia parar os abusos dos violadores. $\mathrm{O}$ agente institucional, o policial usualmente, mas também o traficante ou o paramilitar que dominava o bairro, era capaz de confrontar o 
abusador, legitimando a proteção da "vítima" pela violação ou pelos golpes recebidos.

Os ñeros mostraram uma imagem da violência na família dimensionada por problemas, em oposição a um ideal de família nuclear, valorizada pela política pública e ativada através da retórica dos direitos. Esse modelo foi o referencial dos jovens para medir o grau da violência. Os problemas englobavam descrições de expectativas não cumpridas e desconhecimentos mútuos entre ñeros com seus familiares na casa, definida pela presença da cucha. Apesar da noção de família ser uma referência moral $e$ idealizada através da autoridade do pai, a casa estava governada pela cucha, essa santa que irradiava amor e proteção. Ela estimulava a saída dos varões para eles serem trabalhadores $e$ o sentimento de responsabilidade para eles retornarem como pais protetores, obedientes e com experiência. A cucha é um referente de mulher no qual poder e afeto estão conjugados, guiando o proceder dos ñeros diante de outros homens.

\section{Considerações finais}

Desde a proposta governamental dos ñeros se pensarem como sujeitos de direitos humanos, a categoria de violência revelou relações de desconhecimento $e$ abuso de poder que não estavam mediadas pela afirmação de direitos positivos entre indivíduos, nem pelo fato de um homem possuir privilégios sobre os demais membros na família. Aquilo entendido desde a perspectiva institucional como "violência intrafamiliar" abarcava rupturas nos intercâmbios entre pessoas com diferenças de status e experiência em uma casa, percebidas através de uma linguagem sentimental, mas não vista, por eles, de maneira inicial, como violência. Essa linguagem evocava uma conotação moral negativa sobre relações nas quais eles eram subordinados, sempre diante de uma autoridade que julgava seu comportamento em relação a um estereótipo de muchacho que viraria um homem responsável no futuro. Várias das exposições dos jovens lembravam o discurso do dever ser juvenil associado ao ensino das escolas católicas, $e$ 
eles, como antítese dessa figura, se pensavam a partir da incompletude: ser indivíduo em sociedade era sempre ser visto em relação à carência ou sempre como projeto. Eles, como ñeros, não possuíam os valores para muchachos e não eram reconhecidos como cidadãos representantes de uma "nova masculinidade". Para chegar a ser papá tinham que ser buenos muchachos, o que implicava ser crítico diante da proposta de ser um homem igualitário.

O valor da família, referente moral dos ñeros, é similar à ideia de instituição legal familiar dirigida pelo pater familias e instaurada durante o projeto da Regeneración conservadora nas últimas duas décadas do século XIX. Desde essa época e durante as primeiras três décadas do século $\mathrm{XX}$, esse projeto buscava a continuidade de formas de administração política e social mediadas pela Igreja Católica, resgatando os valores da hispanidade em contraposição ao ideário liberal republicano, inspirado nas reformas napoleônicas. $\mathrm{O}$ homem da regeneración era sujeito de proteção de direitos do Estado, mediador entre a família e o âmbito público, cuja virtude máxima era ser responsável pelo bem-estar da esposa e dos filhos, os quais deviam-lhe obediência. Dada a mudança de sujeitos de proteção de direitos para o Estado, iniciada na década de 1930 com a conformação da infância como população, passando pelos anos 1950, quando as mulheres adquiriram cidadania, $e$ finalizando nos anos 1990 com a inauguração do Estado social de direito com a nova Constituição Política, configura-se uma sensibilidade nacional sobre a "violência intrafamiliar". Esse tipo de direito penal evidencia uma tensão entre a instituição do pater familias e o da "democracia familiar". Se falamos de cultura patriarcal nos ñeros, poderíamos falar essa ideia de família como valor, que também motiva a posição deles em sociedade.

Noções como direito e machismo, quando interpretados pelos ñeros, mostravam um universo de relações e experiências que se afastava da imagem populacional sobre os homens como potenciais agressores. Ser um bom pai não se esgota na ideia do indivíduo como cidadão: consciente do seu corpo marcado pelo 
gênero e criador junto com sua esposa, atributos do novo homem. Ser responsável pelos outros dava prestígio diante dos outros homens, seus pares, e as cuchas, atributo valorizado na casa e na rua. Valores que poderiam ser interpretados como contrários a uma perspectiva dos direitos humanos, brindavam e outorgavam dignidade. De todo modo, o novo homem também contornava a individualidade dos ñeros, pois eles apelavam à possibilidade de exercer seus direitos para ser agentes com posição legítima dentro de um contexto social no qual a precariedade financeira $e$ a estigmatização social eram quase permanentes.

Nessa situação, "ser homem" faz parte de um repertório individualista, no sentido de que era ativado pela retórica liberal do projeto 375 , que procurava o reconhecimento da consubstancialidade dos direitos, tendo como base o indivíduo enquanto cidadão. Mas ser homem também fazia parte do repertório discursivo de se mostrar como sujeito responsável na rua e na família, sendo pai e trabalhador. $\mathrm{Na}$ proposta de subjetivação cidadã é possível ver como essa categoria filosófica gradativamente vai passando do público para o privado, modelando as maneiras nas relações cotidianas de uma cultura que se reproduz na casa para formar cidadãos através da familia.

Nesse contexto de implantação do projeto 375 , a categoria de cultura fundamenta um processo de subjetivação cidadã que conforma uma moralidade que assumia as dádivas (que constituíam o elo social) como desigualdade entre indivíduos. A cultura adjetivada permitia naturalizar um certo conteúdo de violência em relações sociais de pessoas com diferentes posições como pessoas, sob a ótica contratualista, que via a assimetria como desigualdade. Isso permitia o julgamento moral de um complexo de valores, sentimentos e materialidade em troca. A construção do Estado social de direito demanda a identificação de elementos culturais que contrastam com o ideal de sociedade, cuja relação com a objetivação da violência, como própria de sujeitos com autoridade local, é central. Tal fenômeno é visível em Estados de independência recente, nos quais o uso da cultura como categoria de governo dialoga mais com experiências coloniais que 
ainda ecoam na vida política de tais países. Daniel Simião e Kelly Silva (2012) mostraram isso na análise das negociações matrimoniais no contexto urbano em Díli. Em Timor Leste o discurso sobre a tradição está vinculado à ação colonial governamental portuguesa de produção de conhecimento local de usos e costumes para outorgar inteligibilidade às práticas indígenas de prestações entre casas. As ideias de adat, kastom e kultura nos discursos governamentais em Timor Leste vinculam valores dos direitos humanos com o conhecimento do local.

No caso apresentado, temos um processo pelo qual indivíduos sem identificação étnica - os homens de Bogotá viram população culturalizada, com o conteúdo de Kultur, através da tentativa civilizatória de explicar e eliminar a violência dos homens. A dignidade da civilisation, representada pela possessão de direitos positivos pelo indivíduo, está ameaçada pela violência inerente à Kultur. Uma ideia de civilisation que dava conta de uma anti-estrutura a se atingir: a sociedade igualitária, que se superpunha à estrutura da Kultur no local, esta última objetivável na práticas, representações e percepção de si dos ñeros. Esse contraste me permitiu pensar nas implicações da ação social para materializar um projeto de sociedade igualitária em contato com concepções das relações sociais em que as relações de dádiva em vários registros conformam a noção de dignidade dos ñeros.

O conceito de "masculinidade hegemônica", proposto por Raewyn Connell, enfatiza os papéis, a mudança e o contexto onde ela é exercida, e foi proposto para pensar as assimetrias $e$ diferenças de jovens escolarizados na Austrália (Connell; Messerschmidt, 2005). No contexto político e acadêmico colombiano, esse conceito foi apropriado para dar conta de uma "crise na masculinidade", de maneira similar a outros países na América Latina (Viveiros, 2003; Souza, 2009). A ideia de uma masculinidade hegemônica, emergente em países anglo-saxões

7 Sobre os conceitos de anti-estrutura e estrutura ver Victor Turner (1969). Acerca da discussão dos conceitos de civilisation e Kultur, ver Norbert Elias (1994). 
para dar conta de assimetrias em relação ao trato igualitário que esperam os cidadãos em sociedade, ao ser transposta para as sociedades herdeiras da colonização ibérica, caraterizadas pelo status dos indivíduos em sociedade (ver Lima 2004; 2010) revela tradições e estruturas sociais desajustadas a um ideal de sociedade liberal. Tais desajustes configuraram uma ideia de masculinidade englobada pela cultura, antagônica à ideia de dignidade humana.

A abordagem das masculinidades apresenta uma realidade social com carência de cidadania e com excesso de tradição, produzindo pessimismo diante da mudança, pelo qual resulta pertinente sofisticar a pesquisa social e as engenharias psicossocial e jurídica. Esquemas para ajustar uma masculinidade ao ideário liberal podem ser entendidos como parte de uma ideologia semiótica, como descrita por Webb Kaene (2007): o vínculo entre poder político e as disciplinas espirituais do self, que substancializa os direitos no corpo e exige uma relação direita dos cidadãos como iguais diante da autoridade estatal, como parte de uma moral moderna. Nela, a categoria de "violência" se superpõe às relações de reciprocidade no processo sempre inacabado de civilização, em termos de Norbert Elias (1994).

Neste ponto, quero lembrar o programa intelectual de Louis Dumont (1970), que através do contraste do lugar do indivíduo entre ocidente e o sistema de castas indiano desvelou o sistema de ideias de valores do igualitarismo e individualismo ocidental em relação à hierarquização e ao holismo indiano. $\mathrm{O}$ individualismo, como valor principal das sociedades que se assumem como modernas, concebe o indivíduo como sujeito moral que contém os valores da igualdade e da liberdade, que o emancipa da sociedade e da ordem coletiva, encarnando a humanidade. Desvelando o individualismo, Dumont "desnaturalizou" a relação entre indivíduo e sociedade como um problema sociológico, mostrando certa "cegueira" diante do social, produto desse olhar. Ele alude ao termo "apercepção sociológica" para argumentar que noções como persona $e$ indivíduo são construtos socioculturais que imprimem uma perspectiva particular à análise sociológica e que fazem ver indivíduos com o conteúdo ideológico ocidental em 
qualquer contexto histórico ou sócio-cultural. Dumont apela à aquisição de consciência por parte dos pesquisadores para distinguir entre o princípio ideal e as relações sociais empíricas na modernidade (Stolcke, 2001). Considero que o olhar etnográfico, a interpretação sociológica e o agir político a partir do conceito de masculinidade são susceptíveis à crítica levantada por Dumont, mostrando um certo caráter etnocêntrico na leitura dos exercícios de autoridade, com o qual o machismo, os desajustes e as crises da masculinidade são apenas esperáveis.

Nero, muchacho ou novo homem são categorias sociais que conformam a noção de si, em correspondência às narrativas morais da modernidade. Compreender a filosofia, a institucionalidade, a ação social $e$ os processos de subjetivação derivados do princípio de dignidade da pessoa humana liberal $e$ da categoria de cultura como componente da relação nós/outros exige pensar a configuração das relações de reciprocidade, como têm sinalizado autores como Luís Roberto Cardoso de Oliveira (2004, 2008 e 2009) ou Daniel Simião (2014 e 2005). O reconhecimento da dignidade humana de homens e mulheres passa pela constituição dos vínculos entre pessoas, o lugar moral que elas ocupam, a circulação de bens, sentimentos, palavras de caráter inalienável. Também pela capacidade de escolha do indivíduo, que daria conta da sua autonomia e liberdade, bem como da existência de um "eu" ou seu self, como valorizado pela ideologia da modernidade. Desde essa perspectiva, as vicissitudes das pessoas diante das instituições modernas de direito ficam mais complexas analiticamente, pois a posição ética e a ação social estão entre algumas considerações morais de caráter individualista e outras de "configuração local", as quais não são mutuamente excludentes, não estão separadas empiricamente.

\section{Referências bibliográficas}

ABU-LUGHOD, Lila. Writing Against Culture. In: FOX, R. (ed.). Recapturing Anthropology: Working in the Present. Santa Fe, School of American Research Press, 1991 pp.137-62. 
BOAS, Franz. Anthropology and Modern Life. Nueva York, Dover Publications Inc, 1986 [1962].

CARDOSO DE OliveIRA, Luís Roberto. Honra, dignidade e reciprocidade. Série Antropologia 344, Departamento de Antropologia, Universidade de Brasília, 2004.

. Existe violência sem agressão moral?. Revista Brasileira de Ciências Sociais vol. 23, n 67, jun. 2008, pp.135-193.

- Concepçóes de igualdade e (des)igualdades no Brasil. Série Antropologia 425, Departamento de Antropologia, Universidade de Brasília, 2009.

CONNELL, Raewyn; MESSERSCHMIDT, James. Hegemonic Masculinity: Rethinking the Concept. Gender and Society 19(6), 2005, pp.829859.

DABS. Proyecto 375: Acceso a la justicia familiar y atención integral de las violências intrafamiliar y sexual. Departamento Administrativo de Bienestar Social, Bogotá, 2005.

Dumont, Louis. Homo Hierarchicus. The Caste System and Its Implications. Chicago, The University of Chicago Press, 1970 [1966].

. O Individualismo. Uma perspectiva antropológica da ideologia moderna. Rio de Janeiro, Rocco, 1985.

ELIAS, Norbert. El proceso de la civilización. Investigaciones sociogenéticas y psicogenéticas. Bogotá, Fondo de Cultura Económica, 1994 [1977].

GóngORA, Andrés. Redes que curam: riscos, danos e políticas de drogas na Colômbia. Dissertação (Mestrado em Antropologia Social), Museu Nacional, Universidade Federal do Rio de Janeiro, 2013.

GuptA, Akhil; FERGuSON, James. Discipline and Practice: 'The Field' as Site, Method, and Location in Anthropology. In: GUPTA, Akhil; FERGUSON, James (ed.). Anthropological Locations. Boundaries and Grounds of a Field Science. Berkeley, University of California Press, 1997, pp.101-146.

JiMENO, Myriam et alii. Manes, mansitos y manazos. Una metodología de trabajo sobre violencia intrafamiliar y sexual. Bogotá, Universidad 
Nacional de Colombia, Departamento Administrativo de Bienestar Social, 2007.

KAENE, Webb. Christian Moderns: Freedom and Fetish in the Mission Encounter. Berkeley, Los Angeles, University of California Press, 2007.

KuPER, Adam. Anthropology and Anthropologist: The Modern British School. Londres, Routledge, 1983.

LÉVI-STRAUSS, Cláude. Las estructuras elementales del parentesco. Barcelona, Paidós, 1981 [1949].

LiMA, Roberto Kant de. Direitos civis e direitos humanos. Uma tradição judiciaria pré-republicana? São Paulo em Perspetiva 18(1), 2004, pp.49-59.

. Sensibilidades jurídicas, saber e poder: bases culturais de alguns aspectos do direito brasileiro em uma perspectiva comparada. Anuário Antropológico 2009 - 2, 2010, pp.25-51.

MALINOWSKI, Bronislaw. Los argonautas del Pacífico occidental. Comercio y aventura entre los indígenas de la Nueva Guinea melanésica. Barcelona, Ediciones Península, 1973 [1922].

MARTínEZ-MORENO, Marco Julián. Da "cultura de la violencia" à "democracia familiar": Masculinidade, cultura e conformação da alteridade em uma política pública de Bogotá, Colômbia. Dissertação (Mestrado em Antropologia Social), Instituto de Ciência Sociais, Universidade de Brasília, 2013.

. Modernizando al hombre como sujeto de derecho, cultural y con género: un momento etnográfico en el campo de las masculinidades. IM-Pertinente, 2(2), 2014, pp.39-61.

MAUSS, Marcel. Ensaio sobre a dádiva. Forma e razão da troca nas sociedades arcáicas. In: Paulo, Cosacnaify, 2011, pp.183-313 [1925].

Moore, Henrietta L. The Subject of Anthropology. Gender, Symbolism and Psychoanalysis. Cambridge and Malden, Polity Press, 2007.

RubIN, Gayle. The Traffic in Women: Notes on the Political Economy of Sex. In: ReITER, R (ed.). Toward an Anthropology of Women. New York, Monthly Review Press, 1975, pp.157-210. 
SAHLINS, Marshall. Sobre la sociología del intercambio primitivo. In: . Economía de la edad de piedra. Madrid, Akal Editor, 1983, pp.203-296 [1974].

.O "pessimismo sentimental" e a experiência etnográfica: por que a cultura não é um "objeto" em via de extinção (parte I). Mana 3(1), Rio de Janeiro, 1997, pp.41-73.

SILVA, Kelly; SIMIÃO, Daniel. Coping with "Traditions": The analysis of East-Timorese nation building from the perspective of a certain anthropology made in Brazil". Vibrant, 9(1), 2012, pp.360-381.

SIMIÃO, Daniel. As donas da palavra. Gênero, Justiça e a Invenção da Violência Doméstica em Timor Leste. Tese (Doutorado em Antropologia), Universidade de Brasília, 2005.

Sensibilidades jurídicas e respeito às diferenças: cultura, controle e negociação de sentidos em práticas judiciais no Brasil e em TimorLeste. Anuário Antropológico vol. 39, n² 2, 2014, pp.237-260.

SouZA, Márcio Ferreira de. As análises de gênero e a formação do campo de estudos sobre a(s) masculinidade(s). Mediaçóes vol. 14(2), julhodezembro, 2009, pp.123-144.

STRATHERN, Marylin. Subject or Object? Women and the Circulation of Valuables in Highlands New Guinea. In: HIRSCHON, R. (ed.). Women and Property, Women as Property. London, Croom Helm, 1984a, pp.158-175.

Marriage Exchange: a Melanesian Comment. Annual Review of Anthropology 13, 1984b, pp.47-73.

. O gênero da dádiva. Problemas com as mulheres e problemas com a sociedade na Melanésia. Campinas, Editora Unicamp, 2006 [1988].

Stocking, George W. Race, Culture and Evolution. Essays in the History of Anthropology. Nueva York, The Free Press, 1968.

STOLCKE, Verena. Gloria o maldición del individualismo moderno. Revista de Antropologia 44(2), São Paulo, USP, ,2001, pp.7-37.

TURNER, Victor. The Ritual Process. Structure and Anti-Structure. New York, Aldine de Gruyter, 1969. 